\title{
Influence of Project Planning Practices on Implementation of Constituency Development Funded Projects in Kericho County.
}

Jacqueline Chepngeno, Josphat Kwasira

To Link this Article: http://dx.doi.org/10.6007/IJARBSS/v10-i11/8092

DOI:10.6007/IJARBSS/v10-i11/8092

Received: 04 September 2020, Revised: 25 September 2020, Accepted: 10 October 2020

Published Online: 15 November 2020

In-Text Citation: (Chepngeno, \& Kwasira, 2020)

To Cite this Article: Chepngeno, J., \& Kwasira, J. (2020). Influence of Project Planning Practices on Implementation of Constituency Development Funded Projects in Kericho County. International Journal of Academic Research in Business and Social Sciences. 10(11), 310-322.

\section{Copyright: (c) 2020 The Author(s)}

Published by Human Resource Management Academic Research Society (www.hrmars.com) This article is published under the Creative Commons Attribution (CC BY 4.0) license. Anyone may reproduce, distribute, translate and create derivative works of this article (for both commercial and non-commercial purposes), subject to full attribution to the original publication and authors. The full terms of this license may be seen at: http://creativecommons.org/licences/by/4.0/legalcode

Vol. 10, No. 11, 2020, Pg. 310 - 322

Full Terms \& Conditions of access and use can be found at http://hrmars.com/index.php/pages/detail/publication-ethics 


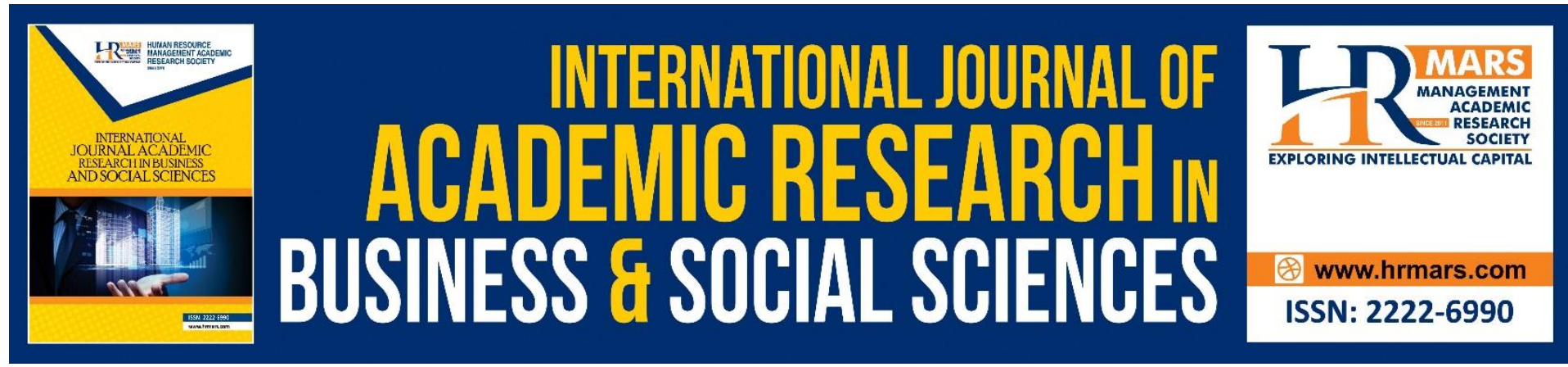

\title{
Influence of Project Planning Practices on Implementation of Constituency Development Funded Projects in Kericho County.
}

\author{
1 Jacqueline Chepngeno, ${ }^{2}$ Dr. Josphat Kwasira \\ ${ }^{1}$ Master of Science in Project Management, ${ }^{2}$ Lecturer Jomo Kenyatta University of \\ Agriculture and Technology
}

\begin{abstract}
The concept of devolution has enhanced the formulation and implementation of projects in both rural and urban areas. The success factor in this project is about project planning practices that are supposed to enhance better governance of these projects. This study aimed at determining the influence of project planning practices on implementation of constituency development funded projects in the Kericho, Kenya. Since independence, constituencies in Kenya have been the lower unit of administration in relation to funding the central government. A number of projects have been initiated and only it is about the best practices that should be applied for the success of the projects. The study was guided by the following specific objective: to examine the influence of project planning on implementation of constituency development funded projects in Kericho, Kenya. The study was built on the planning theory. This study used descriptive survey design. The accessible population comprised of 27 CDF officers, 21 project managers, 111 project committee members and 30 ward administrators. Sample size of 127 was obtained using Krejcie and Morgan formula for finite population. This study employed stratified and simple random sampling in selecting the respondents. The researcher used questionnaire to collect primary data. The data collected was processed through editing, coding and classification. Data were analyzed by employing descriptive statistics and inferential analysis. Descriptive statistics consisted of frequency, percentages, mean, and standard deviation. Inferential statistics used were correlation and multiple regressions. Data were presented by use of frequency tables. The study findings indicated that there is significant influence of project planning practices and implementation of constituency development funded projects in Kericho County $(\beta 1=0.311, p=0.0001<0.05)$. The study concluded that project planning practices influences positively towards implementation of constituency development funded projects in Kericho. The study recommends that the committee members should always approve the project management plan, the review execution of the planning project status before it proceeds to the next phase signify the end of the planning Phase.
\end{abstract}

Keywords: Implementation, Planning, Projects, Development, Practices. 


\section{Background of the Study}

Project implementation process is complex, usually requires extensive and collective attention to a broad aspect of human, budgetary and technical variables (Pinto, 2010). Project implementation covers the activities which include resource acquisition, and implementation plan (International Union for Conservation of Nature, 2014). The project implementation phase takes $80-85 \%$ of all the project activities and resources utilization (Meredith \& Mantel, 2011). Implementation of any project depends on the proper planning, adequate financing, organizational factors and effective communication among the stakeholders (Pedro, 2014).

In Finland brings forth the underlying theory of project execution, for the case of project Management, the decision making is largely taken care of in the planning stage and thus dispatching is reduced to mere communication or authorization to start work. With the process areas used as the criteria for assessment, $90 \%$ and more of the project organizations assessed were in the level 2 and lower of the Capability Maturity Model (CMMI). Very few organizations were even close to the level 3 of the CMM. This called for a recommendation to the organizations for improvement in their project management activities (Amponsah, 2010).

In Belgium, project planning represents processes during the identification and preparation stages of the project life cycle in which the broad context of project operation is clarified. The evaluation strategy is established upon a set of dimensions, questions and respective criteria and proposes an overall participatory approach to be implemented by the use of a mix of methods and a range of tools, which permit to capture the complexity of the inter-active innovation, through investigating on a variety of relevant fields and perspective levels (Anandajayasekeram, 2014). Private organizations are typically small and medium size enterprises that employ fewer advisors than non-private organizations. Their services are more personalized, that is, they have a higher proportion of 1:1 advice and they have a lower ratio of farms per advisor (Prager et al., 2016).

In Rwanda focusing on the reconstruction process, project implementation was achievable with maximum stakeholders' participation, provision of sufficient resources, prudent project team leadership (Jaji, 2017). Stakeholders involvement in project implementation contributed most to project outcome followed by project review then project planning while projects identification had the least influence on project outcome (Kobusingye, Kyalo and Mulyungi, 2017). Proper and enough funds and skills allocation plays a crucial role in project implementation. Stakeholder role such as constituents should play a critical role in decision making because they are the beneficiaries of the projects and know well projects are implemented.

In Kenya, the government and civil society should facilitate public awareness campaigns on project identification and selection by constituents (Madeeha, 2014). There should also be guidelines on how public participation should take place. There should be adequate transportation at the constituency level for effective $M \& E$ of the projects (Kairu \& Ngugi, 2014). On a study on factors influencing the implementation of CDF funded projects in Garsen Constituency, most projects depreciated in their unfinished conditions and were therefore not addressing the needs of the beneficiaries (Richard, 2013).

\section{Statement of the Problem}

Management practices in projects are important because the management define the what is required of the work, scope of the work, allocation of required resources, execution process planning, monitor work progress and amend changes form the initial plan that might arise 
during project implementation (Hornstein, 2015). Review of project in all its stages by a manager help them to play cautiously to avoid errors and ensure accountability (Dissanayaka \& Kumaraswamy, 2013). In regard to the Auditors General Report (2019) report states that CDF projects have seen their implementation hampered significantly in the past decade. A report by the Kenya Tax Payers Association for 2017/18 indicated that $40 \%$ of the CDF could not be accounted for, $20 \%$ of the projects had not been successfully completed and only $5 \%$ had been completed successfully, and over $35 \%$ had been well utilized. $21 \%$ of CDF projects in the country had either stalled or abandoned altogether (Malala \& Njagi, 2015). The implementation of CDF projects in Kenya has been varying with majority of the projects doing very poorly (Wamugu and Ogollah, 2017). Partially, this depends on the project planning practices accorded during the implementation stage. A number of studies have been done on the role of the project planning practices in different sectors and performance of CDF projects. Factors influencing implementation of constituency development funded projects in Juja Constituency Kiambu County (Kinanu, 2017). In detail factors that affect the performance of Constituency Development Fund (CDF) projects in Kenya Malala, Ndolo et al. 2010). Influence of constituency development funded projects in selected indicators of poverty reduction in Kitutu Masaba constituency (Ondieki, 2008). Though the project planning practices have gained a lot of popularity as a tool for improving implementation of CDF projects; it has its own challenges in its application which this study seeks to identify especially in the CDF projects (Kairu, 2014). Further, due to the contextual, sectorial and managerial differences among organizations, the application of the project planning practices cannot be assumed to be similar, unless empirical studies demonstrate so. It is on this premise the current study aims to investigate the relationship between project management practice (project planning) on implementation of constituency development funded projects in Kericho, Kenya.

\section{General Objective}

The objective of the study was to examine the influence of project planning practices on implementation of constituency development funded projects in Kericho County.

\section{Research Hypothesis}

$\mathbf{H}_{\mathrm{o1}}$ : Project planning practices has no significant influence on implementation of constituency development funded projects in Kericho County

\section{Theoretical Framework \\ Planning Theory}

Koskela and Howell (2002) came up with management theory of project management which states management practices are composed of three sub sections which are planning theory, Theory of execution and control Theory. The planning theory enshrines the importance of human capital in project management. In essence, planning acts as an organizing event that management uses as a tool to assemble all the necessary resources (inputs: manpower, materials, time and money) for carrying out the work defined in the project. This theory guided the study in establishing the relationship between project planning and implementation of CDF projects.

According to (Koskela \& Howell, 2002), the theory of execution asserts that managerially, execution is about dispatching tasks to work stations and this is also regarded as the classical communication theory. However, for execution to be effective, the classical communication theory must be complemented with the language/action perspective the vice used in 
communicating the tasks dispatched to work stations must be completely comprehensive to the operatives. There should be feedback mechanisms that will convey the operatives understanding of the instruction passed and as such, enable tasks to be executed as it is envisaged in the plan. Hume is generally attributed with drawing attention to the ought distinction: what is does not necessarily lead to what should be (Wenz, 2013).

Although what is may place restrictions on what can be, our human capacity to reflect on possibilities and make choices means that what is and what should be are connected by values. The fundamental need for a position and a meaning for our lives and for our species dominates whatever system of thought we espouse. Many people are unaware of the values upon which they have founded their structure of meaning (Palmer, 2012). In a sense, then, planning is paradoxical: it is concerned with understanding the activity and process itself, and is therefore descriptive. Yet simultaneously, it is concerned, in a pro-active was, with the formation of future states, and is therefore prescriptive (Wachs, 2013).

\section{Empirical Review}

\section{Project Planning Practices and Implementation of CDF projects}

According to Barasa (2014) project planning activities include the identification of the project's objective; the specification of required project resources and their allocation; and the determination of the methods to be used to deliver the project end product, respond to critical events and evaluate activities and outcomes. The importance of stakeholder involvement in the planning process includes a reduction in distrust of the project process or outcome, an increase in commitment to the project objectives and processes, and heightened credibility of the project's outcome. Effective project planning requires particular skill far beyond writing a document with schedules and budget. It is not only a means of communication and coordination between all those involved in the procurement project but also induces people to look ahead besides instilling a sense of urgency and time consciousness (Barasa, 2014).

Tasevska, Damij and Damij (2014) conducted a study on project planning practices based on enterprise resource planning systems in small and medium enterprises; A case study from the Republic of Macedonia. Four project planning measures were taken into consideration: business case development, scope planning, baseline plan development and risk planning along with three measures of project success; customer satisfaction, perceived quality of the project and success of the implementation process. The study was based on a survey that was conducted on 30 SMEs in the Republic of Macedonia. The findings demonstrated that Macedonian SMEs implemented general project planning practices, even though they did not consider the planning process as a separate phase of the ERP implementation. However, they did not use any particular project planning tools.

Umulisa, Mbabazize and Shukla (2015) did a study on the effects of project resource planning practices on project performance of Agaseke Project in Kigali, Rwanda. A descriptive research design was used and data was collected using questionnaires which were analyzed using descriptive research design. Financial resource planning practices were found to influence the project performance. Practices such as budgeting, forecasting and having plans for money generation were found to exist in the project. The study also established that community participation during implementation of projects in manufacturing companies is a vital as it leads to better outcomes for all stakeholders, stakeholder ownership and lower project costs. Ofori (2013) conducted a study on project planning practices and critical success factors: A developing country perspective. The study sought to identify and assess the quality of project 
planning practices as well as the critical success factors for projects in Ghana. The study adopted an exploratory approach and utilized a survey method to collect data on project planning practices of Ghanaian organizations. Results from the study indicated that the critical factors that contribute to the success of a project include top management support, effective communication, clarity of project purpose and goals, and stakeholder involvement. Documentation and dissemination of critical success factors and best practices in project management will improve the quality of project management in Ghana.

Njiru (2018) conducted a study on the influence of project planning practices on the implementation of projects in manufacturing companies in Nairobi City County, Kenya. The study adopted a descriptive research design. The target population was 49 manufacturing companies from the industrial area of Nairobi City County. The study used stratified sampling method to ensure that all cases are well represented and use simple random sampling method to select the respondents. The study established a positive and significant influence of stakeholder participation, leadership support, communication and resource allocation and project implementation. Leadership support is considered one of the critical success factors in project implementation; effective executive involvement can significantly improve project success.

\section{Conceptual Framework}

This conceptual framework tries to explain the project planning practices on implementation of CDF projects. It assumes that project planning, (independent variables) which influences implementation of CDF projects (dependent variable).

This is as illustrated in Figure 1.

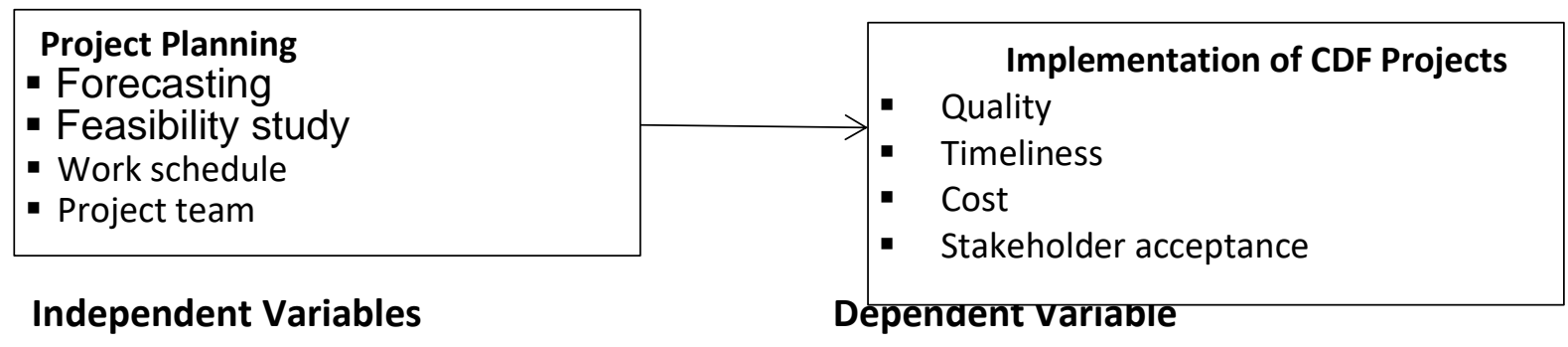

Figure 1: Conceptual Framework

\section{Research Methodology \\ Research Design}

This study used descriptive survey designed to establish the influence of project planning practices on CDF projects in Kenya. Descriptive survey was concerned with describing, analyzing and reporting conditions existing in a particular individual or group, Kothari, (2003). The design was considered appropriate for the study because it allowed the reseacher to describe, record, analyze and report conditions as it exists in the field.

\section{Target Population}

The accessible population comprised of 27 CDF officers, 21 project managers, 111 project committee members and 30 ward administrators.

\section{Sample Size and Sampling Technique}

Sample size of 127 was obtained using Krejcie and Morgan formula for finite population which is calculated as under: 


$$
S=\frac{X^{2} N P(1-P)}{d^{2}(N-1)+X^{2} P(1-P)}
$$

Equation 3.1

Where:

$S$ represent required sample size

$X$ represent $Z$ value (for example 1.96 for $95 \%$ confidence level)

$\mathrm{N}$ represent population size

$P$ represent population proportion (expressed as decimal) (assumed to be $0.5(50 \%)$

$\mathrm{d}$ represent degree of accuracy (5\%), expressed as a proportion (.05); It is margin of error Therefore:

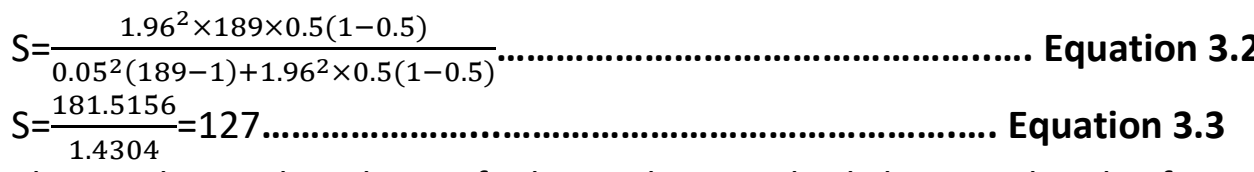

This study employed stratified sampling method done under the four strata CDF officers, project managers, project committee members and ward administrators. From each stratum simple random sampling was applied to get 127 respondents because these entire strata have the same characteristics and the probability of being chosen is equal.

\section{Data Collection Instruments}

The study relied mainly on primary data. The researcher used questionnaire instrument to collect primary data. The study utilized questionnaire that were developed for generating information on key variables of interest from the target respondents in the study. The questionnaire consisted of closed ended questions. Unless otherwise stated, all variables were measured on a 5-point Likert scales anchored by 1=Strongly Disagreed 2= Disagreed $3=$ Undecided 4=Agreed 5= Agreed. The respondents were asked to indicate the extent to which they agreed or disagreed with various statements. The questionnaire was designed to address the specific objectives.

\section{Pilot Study}

This study took $10 \%$ of the target population for pilot test (Coopers \& Schindler, 2010). A pilot study was undertaken in Bomet county and the findings of the pilot study were not included in the actual study.

\section{Data Analysis and Presentations}

The data collected were processed through editing, coding and classification. Data were analyzed by employing descriptive statistics and inferential analysis. Descriptive statistics such as measures of central tendency and dispersion along with percentages used to organize and summarize numerical data. Descriptive statistics consisted of mean, and standard deviation. Data were subjected to correlation and regression analysis with the aid of statistical Package for social sciences (SPSS V23). Multiple regressions are parametric statistics used since the data adheres to the following assumptions or parameters (Field, 2009): data must be on interval level, a linear relationship exists, the distributions normal, outliers were identified and omitted. Data were presented by use of Tables and graphs.

Multiple regression model aided the analysis of the variable relationships as follows:

$Y=\beta_{0}+\beta_{1} X_{1}+\varepsilon$

Where; $Y=$ Implementation of CDF projects (dependent variable);

$\beta 0$ represent constant (coefficient of intercept); 
$\mathbf{X}_{\mathbf{1}}$ represent project planning

$\boldsymbol{\varepsilon}$ represent Error term;

$\boldsymbol{\beta} 1$ represent regression coefficient of variable.

\section{Findings and Discussions}

\section{Descriptive Statistics}

The study sought to examine the influence of project planning practices on implementation of constituency development funded projects in Kericho, Kenya. This section represents the descriptive statistics in relation to the study namely; project planning practices and the dependent variable which is Implementation of constituency development funded projects. To achieve this, a five-point likert scale was used where; $1=$ Strongly Disagreed, $2=$ Disagreed, 3=Undecided.4=Agreed, $5=$ =Agreed .

\section{Project Planning Practices}

The study first sought to examine the influence of project planning practices on implementation of constituency development funded projects in Kericho County. Table 1 presents the study results.

Table 1 Project Planning Practices

\begin{tabular}{|c|c|c|c|c|c|c|}
\hline Statements & & A & UD & D & Mean & Std.Dev \\
\hline We do forecast on & $\mathrm{F}$ & 96 & 6 & 19 & 3.826 & 1.223 \\
\hline $\begin{array}{l}\text { implementation during project } \\
\text { planning }\end{array}$ & $\%$ & 79.3 & 4.9 & 15.7 & & \\
\hline A feasibility study is carried before the & $\mathrm{F}$ & 94 & 10 & 17 & 3.884 & 1.111 \\
\hline project implementation & $\%$ & 77.7 & 8.3 & 14.0 & & \\
\hline Preparing work schedule well has & $\mathrm{F}$ & 89 & 9 & 23 & 3.628 & 1.198 \\
\hline $\begin{array}{l}\text { ensure effective project } \\
\text { implementation }\end{array}$ & $\%$ & 73.6 & 7.4 & 19 & & \\
\hline A project team selected have project & $\mathrm{F}$ & 92 & 9 & 19 & 3.686 & 1.088 \\
\hline planning skills and experience & $\%$ & 76 & 7.4 & 15.6 & & \\
\hline The project stakeholders are identified & $\mathrm{F}$ & 100 & 6 & 15 & 3.793 & 0.999 \\
\hline and involved in project implementation & $\%$ & 82.6 & 4.9 & 12.4 & & \\
\hline
\end{tabular}

Table 1 shows that $96(79.3 \%)$ of the respondents agreed, and 19(15.7\%) disagreed with the statement that they do forecast on project implementation during project planning. Further, the study findings showed in terms of means and standard deviation that the respondents agreed that they do forecast on project implementation during project planning (Mean=3.826, standard deviation=1.223). Also, the study noted that $94(77.7 \%)$ of the 
respondents agreed and $17(14 \%)$ disagreed with the statement that a feasibility study is carried before the project implementation. Further the study findings showed in terms of means and standard deviation that the respondents agreed that a feasibility study is carried before the project implementation (Mean=3.884, standard deviation=1.111).

Further, 89(73.6\%) of the respondents agreed and 23(19\%) disagreed with the statement that preparing work schedule well has ensure effective project implementation. Further the study findings showed in terms of means and standard deviation that the respondents agreed that preparing work schedule well has ensure effective project implementation (Mean=3.628, standard deviation=1.198). Another, 92(76\%) of the respondents agreed and 19(15.6\%) disagreed with the statement that a project team selected have project planning skills and experience. Further the study findings showed in terms of means and standard deviation that the respondents agreed that (Mean=3.686, standard deviation=1.088).

Finally, 100(82.6\%) of the respondents agreed and 15(12.4\%) disagreed with the statement that the project stakeholders are identified and involved in project implementation. Further the study findings showed in terms of means and standard deviation that the respondents agreed that the project stakeholders are identified and involved in project implementation a project team selected have project planning skills and experience (Mean=3.793, standard deviation=0.999). The findings also reveal that project planning practices have a positive influence on implementation of constituency development funded projects in Kericho County. This implies that they do forecast on project implementation during project planning, feasibility study is carried before the project implementation, prepare work schedule well to ensure effective project implementation and project stakeholders are identified and involved in project implementation.

The study concedes with Lechler, 2014) who reported that one major cause of abandonment of donor funded projects in Nigeria was due to inadequate planning \& organizing. His study report further emphasizes the importance of planning and organizing resources in project implementation. The study also concur with a report by Multiple Release Custom (2015) on a study on the planning phase in projects in Britain says that a project manager should consider the six schedule management processes. The study findings show that the development of the schedule baseline will involve activity definition, activity sequencing, activity resource estimation, and activity duration estimation. The study concluded that approval of the Project Management Plan, the execution of the Planning project status review, and the approval to proceed to the next phase signify the end of the Planning Phase.

\section{Inferential Statistics}

This section consists of correlation and regression analysis. The section was meant to achieve both general and specific objectives in establishing the relationships that exists between the study variables.

\section{Correlation Analysis}

Correlation analysis was done to achieve the study specific objectives. The findings are presented in Table 2. Correlation refers to the strength of an association between two variables. A strong or high correlation means that two or more variables have a strong relationship with each other while a weak or low, correlation means that the variables are hardly related. Correlation coefficient can range from -1.00 to +1.00 . The value of -1.00 represents a perfect negative correlation while a value of +1.00 represents a perfect positive 
correlation. A value of 0.00 means that there is no relationship between variables being tested (Orodho, 2003).

Table 2 Correlations Analysis Results

\begin{tabular}{|l|l|l|}
\hline \multicolumn{2}{|l|}{} & Implementation \\
\hline Implementation & Pearson Correlation & 1 \\
\hline Planning & Pearson Correlation & $.740^{* *}$ \\
\hline & p-value & 0.000 \\
\hline
\end{tabular}

**. Correlation is significant at the 0.01 level (2-tailed).

*. Correlation is significant at the 0.05 level (2-tailed).

The Table 2 findings revealed that project planning practices was strongly positively and statistically significant correlated to implementation of constituency development funded projects $(r=0.740 p<0.01)$. This gave an implication that all the study variables were positively correlated to implementation of constituency development funded projects. Project planning practices contributes $74.0 \%$ to implementation of constituency development funded projects.

\section{Multiple Regression Analysis}

Regression analysis is a statistical tool for the investigation of the relationship between variables. Usually, researcher seeks to maintain the causal effect of one variable upon another. Regression analysis allows you to model, examine and explore spatial relationship, and can help explain the factors behind observed spatial patterns. Regression analysis is also used for prediction.

\section{Model Summary}

Model summary provides the coefficient of determination $\left(R^{2}\right)$ which shows proportion of the variance in the dependent variable that is predictable from the independent variable and correlation coefficient $(R)$ shows the degree of association between the dependent and independent variables.

Table 3 Multiple Regression Model Summary

\begin{tabular}{llll}
\hline $\mathbf{R}$ & R Square & Adjusted R Square & Std. Error of the Estimate \\
\hline .820 & .672 & .660 & .363
\end{tabular}

The results presented in Table 3 present the fitness of model used of the regression model in explaining the study phenomena. Project planning practices found to be satisfactory variables in influencing the Implementation of constituency development funded projects. The $R$ value represents the simple correlation and is 0.820 , which indicates a high degree of correlation. This is supported by coefficient of determination also known as the R square of $67.2 \%$. This means that the independent variables explain $67.2 \%$ of the variations in the dependent variable (implementation of constituency development funded projects). 
The results further imply that the model applied to link the relationship of the variables was satisfactory. Adjusted $\mathrm{R}^{2}$ is a modified version of $\mathrm{R}^{2}$ that has been adjusted for the number of predictors in the model by less than chance. The adjusted $\mathrm{R}^{2}$ of which was slightly lower than the $R^{2}$ value was exact indicator of the relationship between the independent and the dependent variable because it is sensitive to the addition of irrelevant variables. The adjusted $\mathrm{R}^{2}$ indicates that $66.0 \%$ of the changes in implementation of constituency development funded projects are explained by the model. However, the typical error when the model is used to predict research success is 0.363

\section{Model Fitness}

Table 4 shows the Analysis of Variance (ANOVA) of regression analysis between independent variable including project planning practices and a dependent variable; implementation of constituency development funded projects.

Table 4 ANOVA Results

\begin{tabular}{llllll}
\hline & Sum of Squares & Df & Mean Square & F & Sig. \\
\hline Regression & 31.309 & 4 & 7.827 & 59.3544 & .000 \\
Residual & 15.298 & 116 & 0.132 & & \\
Total & $\mathbf{4 6 . 6 0 7}$ & $\mathbf{1 2 0}$ & & & \\
\hline
\end{tabular}

The Table 4 shows that in regression, the value of sum of squares is 31.309 , the value of degrees of freedom is 4 , the value of mean square is 7.827 , the value of $F$ is 59.3544 , and the significance value is 0.000 . On the other hand, in residual, the value of sum of squares is 15.298; the value degrees of freedom are 116. Further, the results imply that the independent variables are good predictors of Implementation of constituency development funded projects.

\section{Regression Coefficient}

Regression of coefficients results are presented in Table 5.

Table 5 Regression Analysis Coefficients

\begin{tabular}{lllllll}
\hline & \multicolumn{2}{l}{$\begin{array}{l}\text { Unstandardized } \\
\text { Coefficients }\end{array}$} & \multicolumn{2}{l}{$\begin{array}{l}\text { Standardized } \\
\text { Coefficients }\end{array}$} & T & Sig. \\
\cline { 2 - 5 } & B & Std. Error & Beta & & \\
\hline (Constant) & .605 & .260 & & 2.332 & .0214 \\
Planning practices & .311 & .077 & .323 & 4.027 & .0001 \\
\hline
\end{tabular}

Table 5 shows that project planning practices has a positive and significant influence on Implementation of constituency development funded projects $(\beta=0.311, p=0.0001)$. This gave an implication that a unit increase in planning practices will cause 0.311 increase in implementation of constituency development funded projects. Therefore, the overall regression results imply that there is a positive and significant influence of project planning practices and implementation of constituency development funded projects in Kericho, Kenya. 
The optimal model was;

$Y=0.605+0.311 X_{1}$

\author{
Equation 4.1
}

\title{
Hypotheses Testing
}

The research hypothesis for the study included;

$\mathbf{H}_{01}$ : Project planning practices has no significant influence on implementation of constituency development funded projects in Kericho County. The regression results in Table 5 indicate that there is significant influence of project planning practices and implementation of constituency development funded projects in Kericho County with a beta coefficient of 0.311 and significance of $(p=0.0001)$. The study rejected the hypothesis. These results concur with Kariungi (2014) there is a positive and a significance of project planning the effectiveness of its application in used by CDF teams in Kenya to enhance effective implementation of CDF funded projects.

\section{Summary}

The study found out that the respondents agreed on all aspects of level of project planning practices. They agreed that they do forecast on project implementation during project planning, a feasibility study is carried before the project implementation, preparing work schedule well has ensure effective project implementation and that project team selected have project planning skills and experience and that the project stakeholders are identified and involved in project implementation.

The study findings also showed that project planning practices was statistically significant and have a positive influence on implementation of constituency development fund projects in Kericho County. The study rejected the null hypothesis that there is no statistically significant influence of project planning practices and implementation of constituency development fund projects in Kericho County. The findings show project planning practices positively influences on implementation of constituency development funded projects in Kericho County. This implies that they do forecast on project implementation during project planning, feasibility study is carried before the project implementation, prepare work schedule well to ensure effective project implementation and project stakeholders are identified and involved in project implementation.

\section{Conclusions and Recommendations}

The study concluded there is significant influence of project planning practices and implementation of constituency development funded projects in Kericho County. This can be seen through the use of forecast on project implementation during project planning, feasibility study is carried before the project implementation, prepare work schedule well to ensure effective project implementation and project stakeholders are identified and involved in project implementation.

In reference to the findings, conclusions and the guidance from the literature review, the study recommends that; The committee members should always approve the project management plan, the review execution of the planning project status before it proceeds to the next phase signify the end of the planning phase. The study further recommends that the committee members should always allocate of resources this leads to review and modify the project plan, revise stages, project completion dates. The study also recommends that the CDF committee members should always ensure that there are the necessary resources to 
ensure the project is successful; making stakeholder detailed requirements known improves decision making process towards effective implementation of projects.

\section{References}

Barasa, J. A. (2014). Influence of Board of Managements' Contribution to Development of Public Secondary Schools in Nyamira North District, Nyamira County, Kenya. International Journal of Innovation and Learning, 19(3), 299-313.

Cooper, D. R., Schindler, P. S. (2005). Business Research Methods. (8th Ed.). New Delh: Mc Graw-Hill

Kairu, P. N., \& Ngugi, P .K. (2014). Factors Affecting Effective Implementation of Constituency Development Fund Projects in Machakos Town Constituency, Machakos County in Kenya. International Journal of Current Business and Social Sciences. International Journal of Current Business and Social Sciences, 1(2), 146-167.

Kobusingye, B. E. R. N. A. D. E. T. T. E., Mungatu, J. K., \& Mulyungi, P. (2017). Influence of stakeholders involvement on project outcomes. A case of water, sanitation, and hygiene (wash) project in Rwanda. European Journal of Business and Social Sciences, 6(6), 195-206.

Koskela, L. J., \& Howell, G. (2002). The underlying theory of project management is obsolete. In Proceedings of the PMI research conference (pp. 293-302). PMI.

Kothari, C. R. (2004). Research Methodology: Methods and Techniques. New York: New Age International.

Njiru, S. G. (2018). Project planning practices And Implementation Of Projects In Manufacturing Companies In Nairobi City County, Kenya. An unpublished MBA Thesis, Kenyatta University.

Ofori, D. F. (2013). Project planning practices and critical success factors-A developing country perspective. International Journal of Business and Management, 8(21), 14.

Ondieki, M. G. (2008). Influence of Constituency Development Funded Projects in Selected Indicators of Poverty Reduction in Kitutu Masaba Constituency, Kenya. International journal of production research, 43(20), 4165-4167.

Palmer, A. (2012). Introduction to Marketing: Theory and Practice. Oxford University Press. Journal of targeting, measurement and analysis for marketing 14, no. 3 (2006): 260276.

Pedro, S. (2014). Project Planning and Project Success: the 25\% Solution. CRC Press: USA

Richard, M. K. (2013). Factors Influencing the Implementation of CDF of CDF Funded Projects in Bureti Constituency, Kenya. International Academic Journal of Human Resource and Business Administration, 2(2), 22-40.

Tasevska, F., Damij, T., \& Damij, N. (2014). Project planning practices based on enterprise resource planning systems in small and medium enterprises-A case study from the Republic of Macedonia. International journal of project management, 32(3), 529-539.

Umulisa, A., Mbabazize, M., \& Shukla, J. (2015). Effects of Project Resource Planning Practices on Project Performance of Agaseke Project in Kigali, Rwanda. International Journal of Business and Management Review, 3(5), 29-51.

Wachs, I. E. (2013). Catalysis science of supported vanadium oxide catalysts. Dalton Transactions, 42(33), 11762-11769.

Wenz, K. (2013). Theory Crafting: Knowledge Production and Surveillance. Information, Communication \& Society, 16(2), 178-193. 